\title{
Observations on the separate assessment of Prower-Stuart factor activities
}

\author{
C. GARDIKAS, C. LYBERATOS, G. KALLINIKOS, \\ AND M. KALLINIKOU \\ From the Medical Unit, Evangelismos Hospital, Athens
}

SYNOPSIS The activities of the Prower-Stuart factor in the first and second phase of thromboplastin production were separately assayed in 100 normal persons and 50 Dindevan-treated patients. It was found that in some of the subjects examined the two activities varied independently, and that some of the normal persons presented a partial deficiency of the factor. The implications of these findings are discussed.

The Prower-Stuart factor is unique amongst the clotting factors because it is required for the production of both intrinsic and extrinsic thromboplastin. Thus, when this factor is lacking Quick's one-stage prothrombin test, as well as the thromboplastin generation test, gives abnormal results. Recently, Rabiner and Kretchmer (1961) presented some evidence suggesting that the two activities of the factor may vary independently. They studied a boy with a marked deficiency of the factor in both phases; his father had a marked deficiency in the first phase and a moderate deficiency in the second, whereas his sister had a moderate deficiency in the first phase only. These workers also observed an apparently normal person in whom the activity of the ProwerStuart factor estimated by Quick's one-stage prothrombin test was $87 \%$ and by the thromboplastin generation test it was $32 \%$ of the normal.

If these two activities could vary independently the assay of the Prower-Stuart factor by the method of Bachmann, Duckert, and Koller (1958), based on Quick's one-stage time, would obviously be inadequate.

\section{MATERIALS AND METHODS}

In 100 persons apparently normal and 50 patients receiving Dindevan treatment for eight days or more the Prower-Stuart factor was assayed as follows:-

For the estimation of the activity of the factor in forming extrinsic thromboplastin the method of Bachmann et al. (1958) was used except that charcoal-filtered ${ }^{1}$ instead

\footnotetext{
'Powdered wood charcoal, obtainable from Messrs. Griffin and George Ltd., Alperton, Middlesex, England.
}

Received for publication 20 March 1962. of asbestos-filtered ox plasma was used as substrate according to Denson's modification (1961). To estimate the activity of the factor in the formation of intrinsic thromboplastin a method has been developed employing the thromboplastin screening test of Hicks and Pitney (1957). The generating mixture consisted of $0.1 \mathrm{ml}$. of each of the following reagents: $(a)$ plasma to be tested, diluted 1 in $10,(b)$ charcoal-filtered ox plasma, diluted 1 in 10, (c) brain 'cephalin' (Bell and Alton, 1954), and (d) $\mathrm{M} / 40 \mathrm{CaCl}_{2}$. The clotting times were compared with those of a calibration curve obtained by performing the test on a series of mixtures containing serial dilutions of pooled normal citrated plasma ( 1 in 10,1 in 20,1 in 40 , 1 in 80,1 in 160, 1 in 320, and 1 in 640) corresponding to Prower-Stuart factor levels of 100 to $1.6 \%$ of the normal. The reproducibility of the test was satisfactory, not exceeding $\pm 5 \%$.

\section{RESULTS}

NORMAL PERSONS The results are given in Figure 1. Of the hundred persons examined, 94 showed no significant difference between the two activities of the factor. In six persons, however, a marked difference was observed, four persons presenting a marked reduction in activity in the intrinsic phase and two a similar reduction in activity in the extrinsic phase.

DINDEVAN-TREATED PATIENTS The results are given in Figure 2. As can be seen, in six of the 50 patients under investigation a marked discrepancy between the defects in the two phases was observed.

\section{DISCUSSION}

There are persons who are apparently normal with a partial deficiency in the Prower-Stuart factor. 


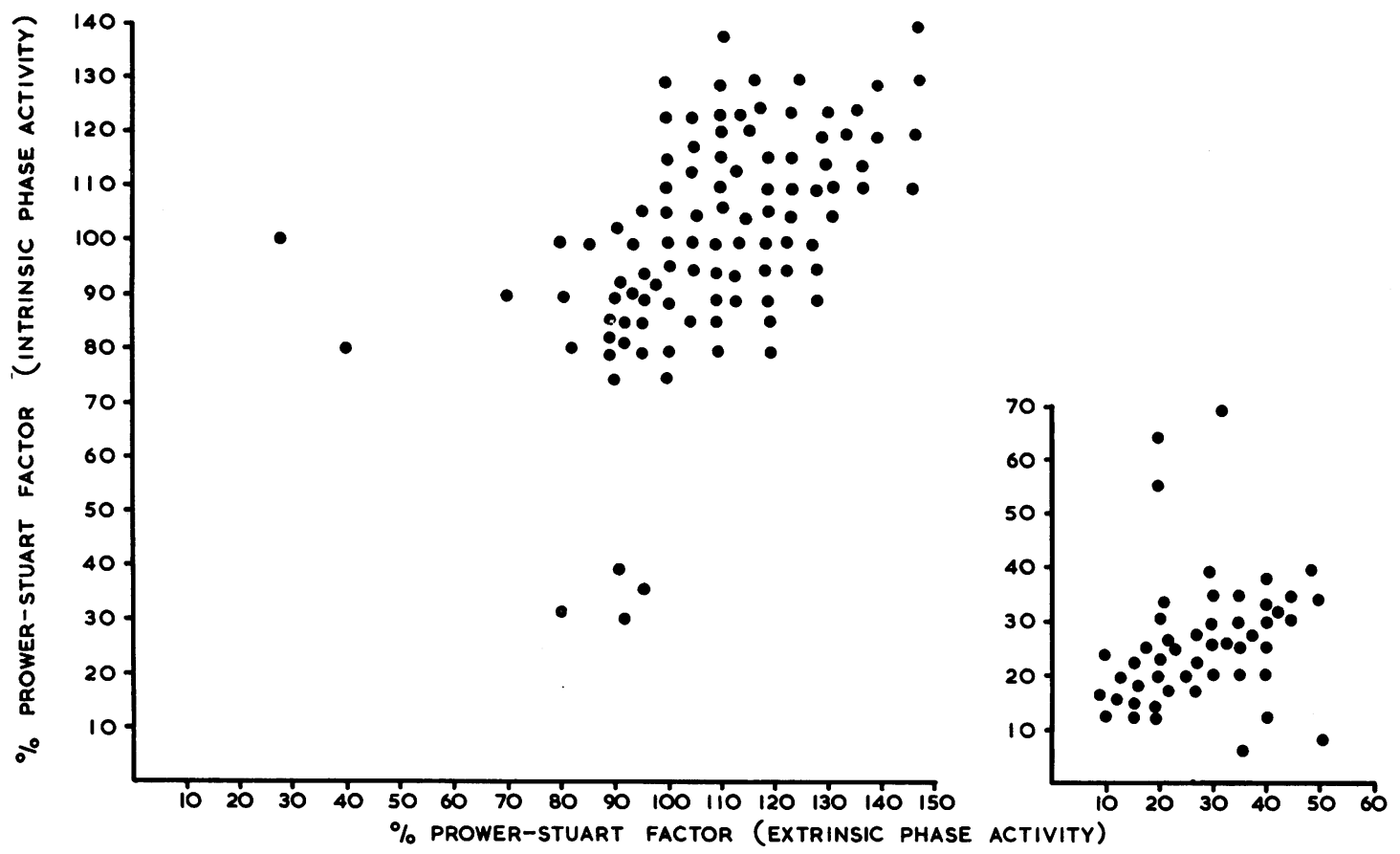

FIG. 1

FIG. 2

FIG. 1. The activity of the Prower-Stuart factor in the two phases of thromboplastin formation in 100 apparently normal persons.

FIG. 2. The activity of the Prower-Stuart factor in the two phases of thromboplastin formation in 50 Dindevan-treated patients.

This finding supports Rabiner and Kretchmer's supposition that a partial deficiency in the ProwerStuart factor may be more common than previous reports imply; it may also explain some of the discrepancies observed in the thromboplastin generation test when using sera from various 'normal' persons. By this test persons with the defect of the factor in the instrinsic phase may be mistakenly regarded as suffering from a mild deficiency of Christmas factor. Although in most patients under Dindevan treatment the first and second phase deficiencies run parallel, in a few a marked difference between the two deficiencies is demonstrable.
The present investigations also suggest that the assay of the Prower-Stuart factor by the method of Bachmann et al. is inadequate unless performed in combination with a method assaying the activity of the factor in the intrinsic phase of thromboplastinogenesis.

\section{REFERENCES}

Bachmann, F., Duckert, F., and Koller, F. (1958). Thromb. Diathes. haemorrh., (Stuttg.) 2, 24.

Bell, W. N., and Alton, H. G. (1954). Nature (Lond.), 174, 880.

Denson, K. W. (1961). Acta haemat. (Basel), 25, 105.

Hicks, N. D., and Pitney, W. R. (1957). Brit. J. Haemat., 3, 227. Rabiner, S. F., and Kretchmer, N. (1961). Ibid., 7, 99. 